\title{
SSLP-1, a secreted Ly-6 protein purified from mouse seminal vesicle fluid
}

\author{
Sheng-Hsiang Li ${ }^{1,2}$, Robert Kuo-Kuang Lee ${ }^{1,3}$, Ming-Huei Lin ${ }^{3}$, Yuh-Ming Hwu ${ }^{2,3}$, Chung-Hao Lu ${ }^{1}$, \\ Ying-Jie Chen ${ }^{1}$, Hsuan-Chiang Chen ${ }^{1}$, Wen-Hwei Chang ${ }^{4}$ and Wei-Chao Chang ${ }^{5}$ \\ ${ }^{1}$ Department of Medical Research, Mackay Memorial Hospital, Tamshui 251, Taiwan, ROC, ${ }^{2}$ Mackay Medicine, \\ Nursing and Management College, Taipei 112, Taiwan, ROC, ${ }^{3}$ Department of Obstetrics and Gynecology, Mackay \\ Memorial Hospital, Taipei 104, Taiwan, ROC, ${ }^{4}$ Digitalgene Biosciences Co., Ltd., Taipei 114, Taiwan, ROC, and \\ ${ }^{5}$ Genomics Research Center, Academia Sinica, Taipei 115, Taiwan, ROC \\ Correspondence should be addressed to S-H Li; Email: Ish@ms1.mmh.org.tw
}

\begin{abstract}
The Ly-6 protein family refers to a group of glycophosphatidyl inositol-anchored membrane proteins with ten conserved cysteines. They are thought to be involved in cellular adhesion and signaling. Recently, a subfamily of secreted Ly- 6 proteins has been identified. In the present study, we report a secreted Ly-6 protein, secreted seminal vesicle Ly-6 protein 1 (SSLP-1) purified from mouse seminal vesicles using a series of steps including ion-exchange chromatography on a diethylaminoethyl (DEAE)-Sephacel column, gel filtration on a Sephadex G-75 column, and ion-exchange HPLC on a sulfopropyl column. Further analysis demonstrated it to be a novel, previously unnamed, $17 \mathrm{kDa}$ glycoprotein. $\mathrm{N}$-glycosidase $\mathrm{F}$ treatment revealed a core protein with a molecular mass of 8720 Da. By Basic Local Alignment Search Tool Protein analysis, we found that SSLP-1 had ten conserved cysteine residues identical with other secreted Ly-6 proteins. The gene $\mathrm{Gm191}$, which is located on chromosome 9, encodes SSLP-1. By Northern blotting with 21 different mouse tissues, we found that $S s / p-1$ mRNA was predominantly expressed in the seminal vesicle. Immunohistochemistry revealed SSLP-1 protein in the luminal fluid and mucosal epithelium of the seminal vesicles. The amount of Sslp-1 mRNA and SSLP-1 protein in the seminal vesicle was regulated by testosterone and correlated with the stage of animal maturation. The tissue-specific expression pattern suggests that SSLP-1 may play a physiological role in male mouse reproduction.
\end{abstract}

Reproduction (2006) 132 493-500

\section{Introduction}

The Ly-6 (also known as Ly-6/urokinase-type plasminogen activator receptor, UPAR) protein superfamily refers to a group of proteins with ten conserved cysteine residues (LeClair et al. 1986, Bamezai 2004). They are classified into two subfamilies based on whether they have a glycophosphatidyl inositol (GPI)-anchored signal sequence. GPI-anchored Ly- 6 receptor proteins are thought to be involved in cellular adhesion and signaling (Gumley et al. 1995, Bamezai 2004). The second non-GPI-anchored subfamily contains secreted Ly-6 proteins, including secreted mammalian Ly-6/uPARrelated protein (SLURP)-1 (Adermann et al. 1999), SLURP-2 (Tsuji et al. 2003), rat urinary protein (RUP)-1, RUP-2, pig protein (PIP)-1, and rat spleen protein (RSP)-1 (Southan et al. 2002), and seminal vesicle secretion 7 (SVS 7; Southan et al. 2002).
SLURP-1 in human blood and urine was the first of the secreted Ly- 6 protein to be discovered (Adermann et al. 1999). SLURP-1 gene mutations have been implicated in a rare skin disorder, Mal de Meleda (Fischer et al. 2001, Eckl et al. 2003, Mastrangeli et al. 2003, Ward et al. 2003). SLURP-1 protein is an epidermal neuromodulator of the $\alpha 7$ nicotinic receptor and thought to be involved in epidermal homeostasis and cutaneous inflammation (Chimienti et al. 2003). SLURP-2 has been shown to be upregulated in psoriasis vulgaris, suggesting a possible pathogenetic role in that disorder (Tsuji et al. 2003).

RUP-1 and RUP-2 have been found in rat. While it is known that they are secreted and glycosylated proteins, their biological functions are obscure (Southan et al. 2002). SVS7 was originally purified from the mouse seminal vesicle and has caltrin activity inhibiting calcium uptake by epididymal sperm (Coronel et al. 
1992). It is a phospholipid-binding protein and a sperm motility enhancer which is expressed and secreted exclusively in the seminal vesicle (Luo et al. 2001).

SVS contribute the major portion of the seminal plasma. Previously, several proteins purified from murine SVS have been demonstrated to have effects on sperm physiology (Chen et al. 1998, Huang et al. 1999, Luo et al. 2001, Li et al. 2005). However, other components of SVS remain to be identified. Further investigation of the proteome may enhance our understanding of normal and abnormal male reproductive physiology. Here, we report a novel secreted Ly- 6 protein found in murine SVS.

\section{Materials and Methods}

\section{Animals and hormone treatment}

Specific pathogen-free outbred ICR mice were purchased from BioLASCO Taiwan Co., Ltd (Taipei, Taiwan). The animals were bred based on the technology derived from Charles River Laboratories (Wilmington, MA, USA), maintained in the animal center at the Department of Medical Research, Mackay Memorial Hospital and treated according to the institutional guidelines for the care and use of experimental animals. They were housed under controlled lighting ( $14 \mathrm{~h}$ light: $10 \mathrm{~h}$ darkness) at $21-22{ }^{\circ} \mathrm{C}$ and provided with water and NIH-31 laboratory mouse chow ad libitum.

Normal 10-week-old adult mice were used to purify the protein. To investigate the androgenic effects, adult male mice $(n=24)$ were used. Twenty were castrated at the age of 5 weeks; the remaining four were kept as controls. When the mice were 8 weeks old, five of the castrates were given s.c. injection of testosterone propionate (Sigma) in corn oil ( $5 \mathrm{mg} / \mathrm{kg}$ body weight) for eight consecutive days. The 15 castrated control animals received corn oil only. The four normal controls were not given any treatment. The mice were killed by cervical dislocation and the seminal vesicles removed $12 \mathrm{~h}$ after the last injection. To examine the differential expression of mRNAs and proteins in the above treatment, the total RNA of tissues was purified for the Northern blot analysis; total protein extracts were used for the Western blot analysis, and paraffin-embedded tissue sections were used for immunohistochemistry analysis.

To examine the developmental profile of the protein, 22 mice at various ages ranging from 3 to 16 weeks were killed, the seminal vesicles removed, and the amount of mRNA transcripts and proteins were measured. The distribution of the mRNA was assessed by Northern blot analysis in various reproductive tissues of adult mice, including three males, three females, and two pregnant females.

\section{Protein purification}

Normal adult mice (10 weeks old) were sacrificed by cervical dislocation. The seminal vesicles collected from $\sim 300$ mice were carefully dissected to free them from the adjacent coagulating glands, and the secretions were squeezed directly into $50 \mathrm{ml}$ of ice-cold $10 \mathrm{mmol} / \mathrm{l}$ Tris- $\mathrm{HCl}$ in the presence of $1 \mathrm{mmol} / \mathrm{l}$ phenylmethyl sulfonyl fluoride at $\mathrm{pH}$ 8.0. After centrifugation at $10000 \mathrm{~g}$ for $15 \mathrm{~min}$, the supernatant was resolved by ion-exchange chromatography on a DEAE-Sephacel (Amersham) column $(12 \times$ $2.6 \mathrm{~cm}$ ) pre-equilibrated with $10 \mathrm{mmol} / \mathrm{l}$ Tris- $\mathrm{HCl}$ at $\mathrm{pH}$ 8.0. After non-retarded fractions were washed out, the column was eluted with $0.5 \mathrm{~mol} / \mathrm{I} \mathrm{NaCl}$ in the same buffer at a flow rate of $18 \mathrm{ml} / \mathrm{h}$; fractions of $4 \mathrm{ml}$ per tube were collected and the absorbance of each fraction at $280 \mathrm{~nm}$ was recorded (Fig. 1A). Fraction I was concentrated and subjected to elution in a Sephadex G-75 (Sigma) column $(2.6 \times 120 \mathrm{~cm})$ pre-equilibrated with $50 \mathrm{mmol} / \mathrm{l}$ Tris- $\mathrm{HCl}, 150 \mathrm{mmol} / \mathrm{l}$ $\mathrm{NaCl}$, at $\mathrm{pH}$ 7.4. The column was eluted with the same buffer at a flow rate of $10 \mathrm{ml} / \mathrm{h}$; fractions $(2 \mathrm{ml})$ were collected and the absorbance recorded (Fig. 1B). Peak 3 from this step was further subjected to ion-exchange HPLC on a Protein PAK SP 5PW (Waters, Milford, MA, USA) column $(7.5 \mathrm{~cm} \times 7.5 \mathrm{~mm})$. The column was eluted with a linear gradient of $0-100 \%(\mathrm{w} / \mathrm{v})$, $1.0 \mathrm{~mol} / \mathrm{l} \mathrm{NaCl}$ in $20 \mathrm{mmol} / \mathrm{l}$ sodium acetate at $\mathrm{pH}$ 6.0 at a flow rate of $1.0 \mathrm{ml} / \mathrm{min}$ for $60 \mathrm{~min}$ (Fig. 1C).

\section{Protein analysis}

Protein components were resolved by $15 \%$ SDS-PAGE. The $\mathrm{N}$-glycoconjugate of a glycoprotein was removed using the method of Tarentino \& Plummer (1994). The protein was boiled in $1.0 \%(\mathrm{w} / \mathrm{v})$ SDS and incubated with $\mathrm{N}$-glycosidase F (40 U/mg protein; TaKaRa, Shiga, Japan) in $20 \mathrm{mmol} / \mathrm{l}$ sodium phosphate at $\mathrm{pH} 7.2$ in the presence of $50 \mathrm{mmol} / \mathrm{I} \mathrm{EDTA}, 0.5 \%(\mathrm{v} / \mathrm{v})$ Nonidet P-40, and $10 \mathrm{mmol} / \mathrm{l}$ sodium azide for $16 \mathrm{~h}$ at $37^{\circ} \mathrm{C}$. Periodic acid-Schiff (PAS) staining of glycoproteins was performed by using the Gelcode glycoprotein staining kit (Pierce, Rockford, IL, USA). The protein concentration was determined using the bicinchoninic acid protein assay (Smith et al. 1985). The amino acid sequence was determined using automated Edman degradation with a 492-protein sequencer with an online $140 \mathrm{C}$ analyzer (Applied Biosystems, Foster City, CA, USA). Database searching was performed using the Basic Local Alignment Search Tool (BLAST) algorithms against the nonredundant database up to May 2006 (http://www.ncbi. nlm.nih.gov/BLAST). The multiple protein sequence alignments were performed by ClustalW (http://www. ebi.ac.uk/clustalw). 


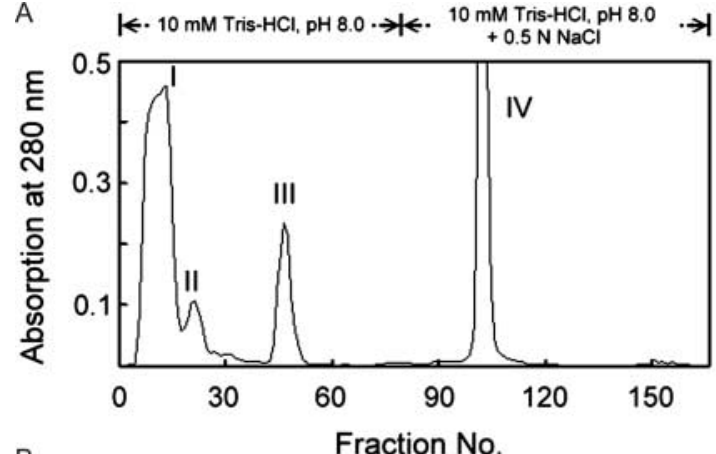

B

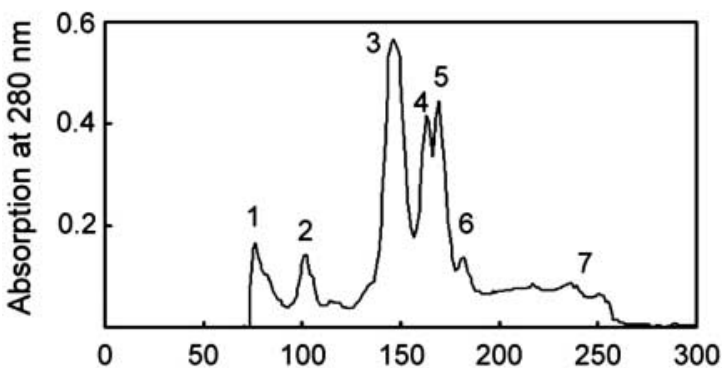

C

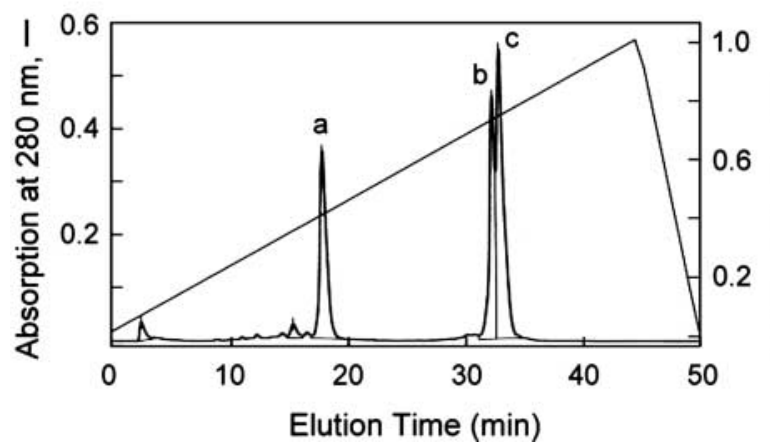

Figure 1 Purification of the peak-a protein from mouse seminal vesicle secretions. (A) Fractionation of soluble proteins by ion-exchange chromatography on a DEAE-Sephacel column. (B) Resolution of fraction I from (A) by gel filtration on a Sephadex G-75 column. (C) Resolution of peak 3 fraction from (B) by ion-exchange HPLC on a SP column.

\section{Mass spectrometry}

The protein band on the SDS-PAGE gel was excised, washed in a solution containing acetonitrile and $100 \mathrm{mmol} / \mathrm{l} \mathrm{NH}_{4} \mathrm{HCO}_{3}(1: 1, \mathrm{v} / \mathrm{v})$, and subjected to in-gel digestion with trypsin overnight at $37^{\circ} \mathrm{C}$. The tryptic peptides were extracted with a solution of $50 \%$ $(\mathrm{v} / \mathrm{v})$ acetonitrile and $1 \%(\mathrm{v} / \mathrm{v})$ formic acid, lyophilized, resuspended in $0.1 \%(\mathrm{v} / \mathrm{v})$ formic acid, and analyzed with a QSTAR XL Hybrid liquid chromatographic mass spectrometry (LC/MS/MS; Applied Biosystems) equipped with an UltiMate TM Capillary/Nano LC system (LC Packings, Sunnyvale, CA, USA). Peptide sequences were identified by using Mascot software (Matrix Science, London, UK) analysis, which searched the NCBI nonredundant sequence database using as a query the mass spectra we had obtained.

\section{Western blotting}

Antisera against SSLP-1 were raised in New Zealand White rabbits. Proteins were resolved using SDS-PAGE on a $15 \%$ gel slab $(8.2 \times 7.3 \times 0.075 \mathrm{~cm})$ by the method by Laemmli (1970). The proteins on the gel were stained with Coomassie Brilliant Blue or transferred to a nitrocellulose membrane using electroblotting at $35 \mathrm{~V}$ at $4{ }^{\circ} \mathrm{C}$ for $18 \mathrm{~h}$ in a solution of $25 \mathrm{mmol} / \mathrm{l}$ Tris $-\mathrm{HCl}$, $197 \mathrm{mmol} / \mathrm{l}$ glycine, and $13.3 \%(\mathrm{v} / \mathrm{v})$ methanol. Membranes were blocked with $5 \%(\mathrm{w} / \mathrm{v})$ skim milk in PBS for $2 \mathrm{~h}$, and incubated with anti-SSLP-1 antiserum (1: 10000$)$ in the blocking solution for $1 \mathrm{~h}$ at room temperature. After gently agitated in four changes of PBS for $15 \mathrm{~min}$ each, horseradish peroxidase-conjugated goat anti-rabbit IgG (Zymed Laboratories, South San Francisco, CA, USA) diluted to 1:10 000 was added to the blocking solution for $1 \mathrm{~h}$. Immunoreactive bands were revealed using an enhanced ECL substrate according to the manufacturer's instructions (NEN Life Science Products, Boston, MA, USA).

\section{Immunohistochemical staining}

Mouse seminal vesicles were fixed in $10 \%(\mathrm{v} / \mathrm{v})$ formaldehyde solution and embedded in paraffin, after which $8 \mu \mathrm{m}$ serial cross-sections were mounted on silanated glass slides (Sigma). Deparaffinized sections were immersed in $0.3 \%(\mathrm{v} / \mathrm{v}) \mathrm{H}_{2} \mathrm{O}_{2}$ solution to block endogenous peroxidase activity, blocked with $10 \%(\mathrm{v} / \mathrm{v})$ normal goat serum in PBS for $1 \mathrm{~h}$ at room temperature and incubated with anti-SSLP-1 antiserum diluted to 1:1000 in the blocking solution for $1 \mathrm{~h}$. The slides were gently agitated in three changes of washing solution for $10 \mathrm{~min}$ each and treated with biotin-conjugated goat anti-rabbit IgG $(\sim 1 \mu \mathrm{g} / \mathrm{ml}$; Kirkegaard \& Perry Laboratories, Gaithersburg, MD, USA) in the blocking solution for $1 \mathrm{~h}$ at room temperature. The slides were washed again as mentioned above and incubated with horseradish peroxidase-conjugated streptavidin $(\sim 1 \mu \mathrm{g} / \mathrm{ml}$; Zymed Laboratories) in blocking solution for $1 \mathrm{~h}$ at room temperature. Protein signals were examined after the slides were incubated for $10 \mathrm{~min}$ with 3-amino-9ethylcarbazole staining solution (Zymed Laboratories). The slides were washed in three changes of water for 3 min each and counterstained with hematoxylin (Vector Laboratories, Burlingame, CA, USA) for $10 \mathrm{~s}$. The sections were photographed using an Olympus microscope (BX40; Olympus, Tokyo, Japan) equipped with an Olympus DP70 video camera.

\section{RNA isolation and Northern blot analysis}

Total RNA was extracted from tissue homogenates using an Ultraspec-II RNA isolation kit (Biotecx Laboratories, Inc., Houston, TX, USA). A PCR-amplified fragment of Sslp-1 cDNA (479 bp) and a cDNA fragment of the 
mouse Gapd gene (557 bp) were used as a template to prepare a ${ }^{32}$ P-labeled cDNA probe using a Promega random-priming kit (Promega). RNA samples $(20 \mu \mathrm{g})$ were subjected to denaturation by $1.0 \%(\mathrm{w} / \mathrm{v})$ agaroseformaldehyde gel electrophoresis and blotted onto nylon membranes by capillary transfer as previously described (Maniatis et al. 1989). Blotted membranes were first incubated with pre-hybridization buffer $(50 \%$ deionized formamide, $6 \times$ SSC, $5 \times$ Denhardt's solution, $1.0 \%$ SDS, and $100 \mu \mathrm{g} / \mathrm{ml}$ sheared salmon sperm DNA) for $2 \mathrm{~h}$ at $45{ }^{\circ} \mathrm{C}$ and hybridized with labeled $S s / p-1$ probes overnight at $45^{\circ} \mathrm{C}$. Following hybridization, membranes were washed using standard procedures. The mRNA on a filter membrane was examined after autoradiography and probes were removed from the membrane as previously described (Maniatis et al. 1989). The same membrane was then hybridized with labeled Gapd probes. Thus, hybridization with $S s / p-1$ and Gapd probes was performed on the same filter membrane. To quantitate the relative $S s / p-1$ gene expression, blots were exposed to a Fuji phosphoimager screen and quantified with Fuji Science Lab software (Fuji Laboratories, Japan). As a control for loading differences, the Sslp-1 mRNA level was normalized to the level of the Gapd mRNA on the same blot.

\section{Statistical analysis}

Data are presented as mean \pm s.D. Differences in mRNA expression were analyzed by the Bonferroni post hoc test followed by one-way ANOVA using InStat software (GraphPad, San Diego, CA, USA). A P value of $<0.05$ was considered to be significant.

\section{Results}

\section{Purification and identification of a novel secreted Ly-6 protein from the mouse SVS}

Three peaks obtained from liquid column chromatography of the fresh preparation of soluble SVS were resolved by ion-exchange HPLC on a sulfopropyl (SP) column at the final purification step (Fig. 1C, peaks a-C). Each of the representative samples at various steps of purification was resolved on reducing SDS-PAGE gel (Fig. 2A). Peak-a yielded one broad $\sim 17 \mathrm{kDa}$ band that could be deglycosylated by exhaustive digestion with $\mathrm{N}$-glycosidase $\mathrm{F}$ to a sharp $\sim 9 \mathrm{kDa}$ protein (Fig. $2 \mathrm{~A}$, lane 5). The peak-a protein stained with PAS reagent, but its deglycosylated form did not (Fig. 2B), which implies that peak-a apparently was a glycoprotein with $\mathrm{N}$-linked carbohydrate moieties. The $\mathrm{N}$-linked glycans seemed to be the only glycosylation, since the PAS reagent did not stain the deglycosylated protein (cf. lanes 4 and 8 of Fig. 2B).

The antibody against peak-a protein immunoreacted to a broad $\sim 17 \mathrm{kDa}$ protein band in the SVS, to the

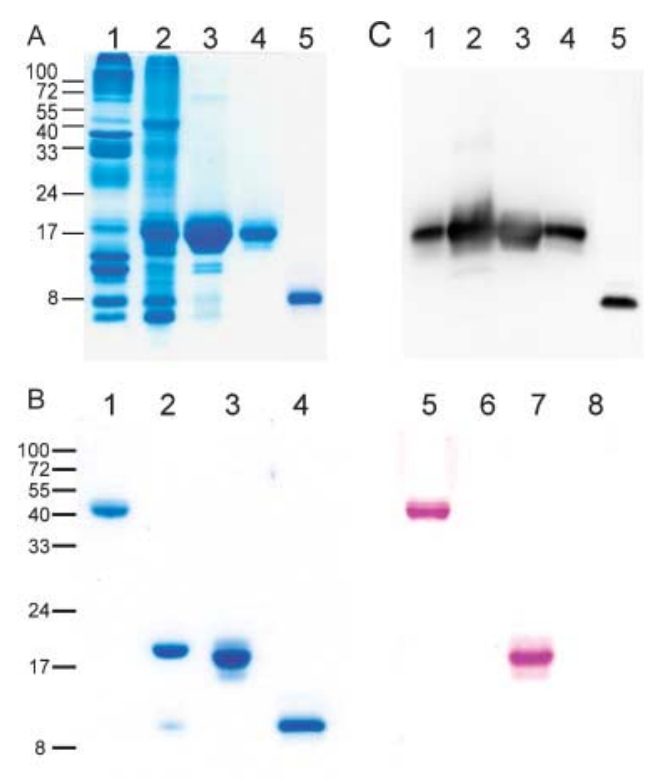

Figure 2 Glycoprotein nature and antiserum specificity of the peak-a protein. (A) A representative sample at various purification steps was resolved by $15 \%$ SDS-PAGE. Lane 1, $15 \mu$ g seminal vesicle secretion; lane $2,15 \mu \mathrm{g}$ fraction I of DEAE-Sephacel chromatography; lane 3, $10 \mu \mathrm{g}$ peak 3 of gel filtration; lane 4, $1.5 \mu$ g peak-a of HPLC. Lane 5, $2 \mu \mathrm{g}$ deglycosylated peak-a. (B) Demonstration of glycosylation. Each protein was identified by SDS-PAGE on a $15 \%$ polyacrylamide gel slab. The proteins in the gel were stained with Coomassie Blue (lanes 1-4) and PAS reagent (lanes 5-8). Lanes 1 and 5, $2 \mu \mathrm{g}$ horseradish peroxidase as a positive control; lanes 2 and $6,2 \mu$ g soybean trypsin inhibitor as a negative control; lanes 3 and 7, $2 \mu \mathrm{g}$ peak-a; lanes 4 and 8, $2 \mu \mathrm{g}$ deglycosylated peak-a protein. (C) Specificity of antiserum. The SDS-PAGE gel on (A) was electroblotted onto a nitrocellulose membrane and immunodetected by antiserum raised against peak-a protein.

purified peak-a protein, and to a single $\sim 9 \mathrm{kDa}$ deglycosylated peak-a protein (Fig. 2C). Therefore, extensive $\mathrm{N}$-glycosylation seems to account for the higher molecular mass of the peak-a protein $(17 \mathrm{kDa}$ compared with $\sim 9 \mathrm{kDa}$ ).

To aid in identifying the glycoprotein, the band of the deglycosylated peak-a protein on the SDS-PAGE gel was excised and digested in-gel by trypsin, with the resulting tryptic peptides purified and subjected to LC/MS/MS analysis. The results suggested that peak-a protein had significant homology to an unnamed protein (accession no. gi74190429), with the tryptic peptides matching $38 \%$ of the putative protein sequences (Fig. 3). To further verify its authenticity, automated Edman degradation of the native peak-a protein was performed for 15 cycles. This yielded reliable peptide sequences, indicating that leucine was the $\mathrm{N}$-terminal residue and that the amino acid sequence LTXVSXGRLXSSGI was identical with the unnamed protein sequence in nearly all positions except for X (cysteine or asparagines; Fig. 3). Apparently, the signal peptidase acting at the Ala-Leu peptide bond in the signal peptide cleaved 21 amino 


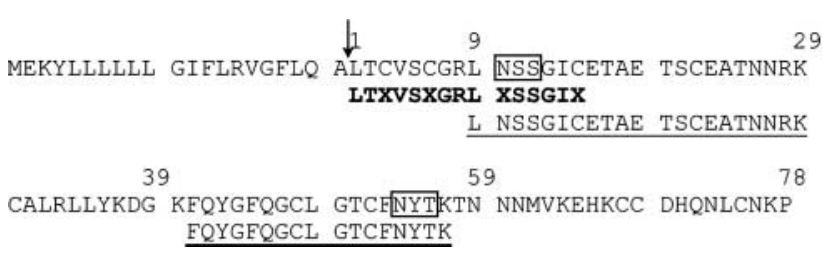

Figure 3 Identification of the SSLP-1 glycoprotein. The unnamed protein sequence is shown (accession no. gi74190429). Open boxes denote the potential $\mathrm{N}$-linked glycosylation sites. The amino acid sequences determined directly from Edman sequencing of the first 15 amino acids agreed in all positions except that $\mathrm{Cys}^{3}, \mathrm{Cys}^{6}$, and $\mathrm{Asn}^{10}$ from the unnamed protein were not identified in protein sequencing. The matched tryptic peptides in LC/MS/MS analysis are underlined. An arrow indicates the cleavage point for the generation of mature protein.

acid residues to produce a mature protein of 78 amino acid residues with a molecular mass of $8720 \mathrm{Da}$, matching the size of the deglycosylated band on the SDS-PAGE gel (Fig. 2A, lane 5).

BLASTP - searching the non-redundant protein database using the unnamed protein sequence as the query, we found that this protein had $30-49 \%$ identities with a group of proteins with Ly-6/uPAR domains, including bovine protein 1 (BOP-1) protein precursor (Swiss-Prot: P83107), rat RSP-1 (Swiss-Prot: Q9QXN2), mouse PIP-1 like (NCBI: XP_486210), pig PIP-1 (SwissProt: P83106), rat RUP1 (Swiss-Prot: P81827), rat RUP2 (Swiss-Prot: P81828), rat RUP-3 (Swiss-Prot: P83121), and rat SVS7 (NCBI: XP_343370), as well as the acrosomal vesicle protein SP-10 of many species, including humans (NCBI: NP_064499), rats (NCBI: NP_068515), and mice (Swiss-Prot: P50289). It is to note that SLURP-1, the renowned secreted Ly- 6 protein, did not appear on the list owing to the fact that there was only $15 \%$ amino acid identity with the query protein. Since the query protein was derived from SVS and contains the Ly- 6 protein domain, we named it secreted seminal vesicle Ly- 6 protein, abbreviated as SSLP-1. A computer-annotated UniProtKB/TrEMBL entry Q3UN54 was assigned according to the translation of $S s / p-1$ mRNA during the course of this investigation. Our MS and Edman data of SSLP-1 have been submitted to SWISS-PROT to update the entry Q3UN54.

We compared SSLP-1 amino acid sequence with known secreted Ly- 6 proteins, such as rat RUP-1, RUP-2, mouse SVS7, and mouse SLURP-1 and found that they all had ten conserved cysteine positions and a C-terminal CCXXXXXCN motif, indicating that SSLP-1 is a member of the secreted Ly- 6 protein subfamily (Fig. 4).

To determine the genomic structure, we searched the GenBank database by BLASTN using the cDNA sequence corresponding to the $S s / p-1$ gene and found that it mapped to chromosome 9. Further examination revealed that the message was encoded by the Gm191 gene (UniGene entry: Mm.118804) and matched completely a mouse genomic contig sequence in GenBank (accession no. NT_084796). The gene spans

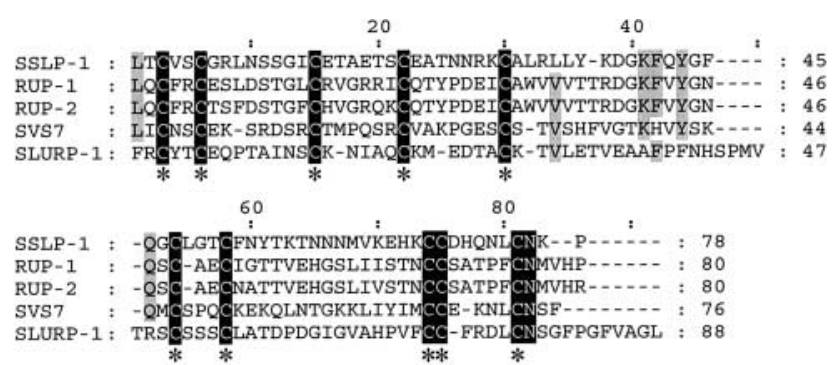

Figure 4 Multiple protein sequence alignment of the secreted Ly-6related protein. Dashes represent gaps introduced to optimize the alignment. The shaded areas indicate matching residues. Asterisks mark the ten conserved cysteine residues of the secreted Ly- 6 protein family.

$\sim 2.834 \mathrm{~kb}$ and consists of three exons separated by two introns.

\section{Predominant SSLP-1 expression in the luminal epithelium of the seminal vesicle}

To study the tissue distribution by Northern blotting, we examined the expression of $S s / p-1$ transcript in the tissue homogenates of reproductive tissues, including the seminal vesicle, epididymis, testis, coagulating gland, vas deferens, prostate, uterus, and ovary. A $\sim 0.7 \mathrm{~kb}$ band corresponding to $S s / p-1$ mRNA was detected in the seminal vesicles exclusively (Fig. 5). When an equal amount of total RNA from the homogenate of a nonreproductive organ was compared with that of the seminal vesicle, very little to no $S s / p-1$ mRNA was found in the brain, heart, lung, liver, spleen, kidney, stomach, small intestine, muscle, skin, thymus, bladder, or placenta (not shown).

SSLP-1 protein was mainly immunolocalized to the luminal fluid and the epithelium of the mucosal folds of the seminal vesicles of adult mice (Fig. 6A and B). The

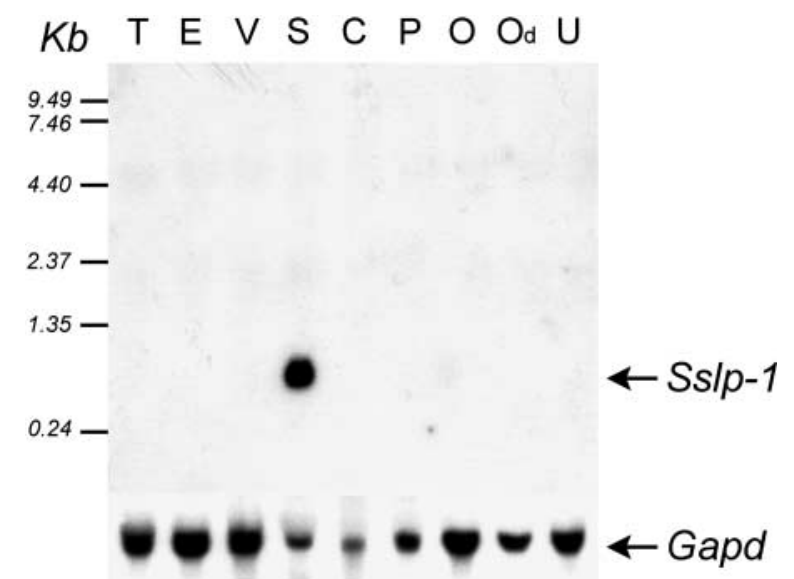

Figure 5 Distribution of $S s / p$ - 1 messages among reproductive tissues. Total RNA $(20 \mu \mathrm{g})$ prepared from the homogenates of each sexual tissue was analyzed by Northern blotting. T, testis; E, epididymis; $\mathrm{V}$, vas deferens; $\mathrm{S}$, seminal vesicle; $\mathrm{C}$, coagulating gland; $\mathrm{P}$, prostate; $\mathrm{O}$, ovary; Od, oviduct; and $U$, uterus. 

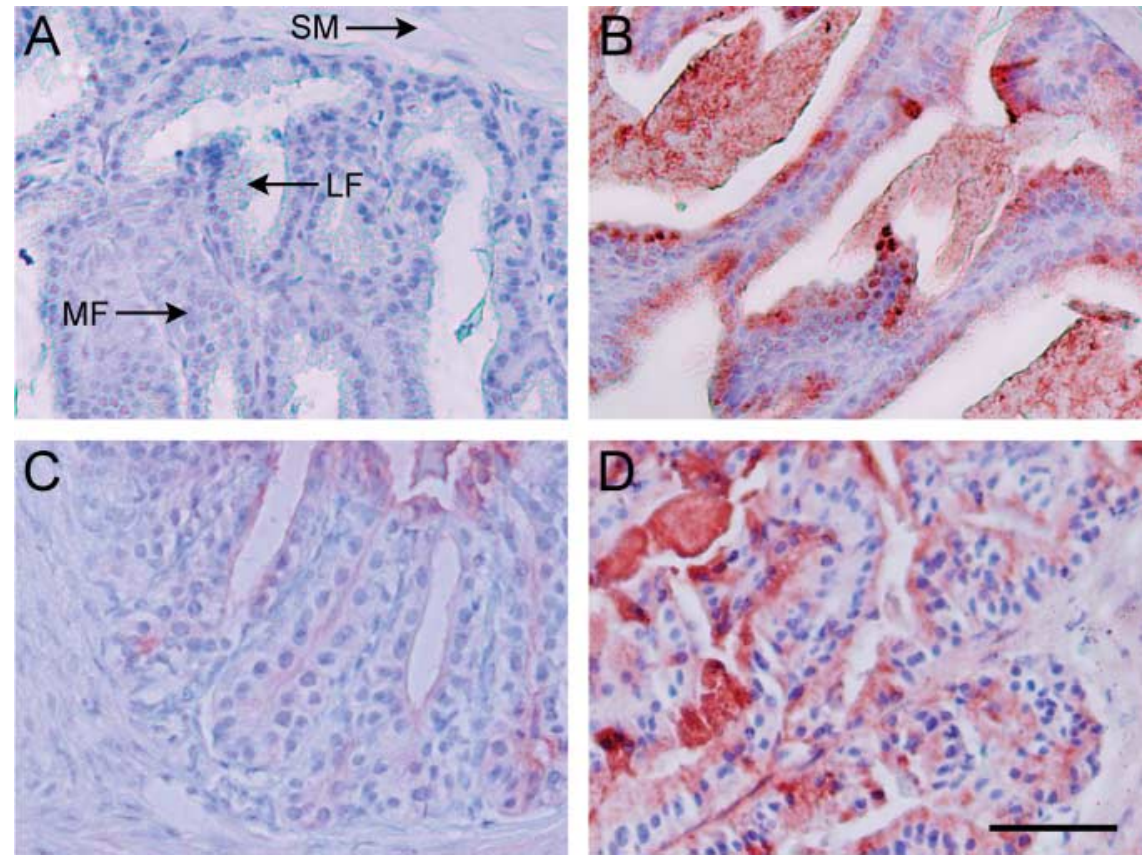

Figure 6 Immunolocalization of SSLP-1 to the luminal fluid and epithelium of seminal vesicle mucosal folds. (A) Tissue slices from 9week-old mice were stained with normal serum, biotin-conjugated goat-anti-rabbit IgG, and horseradish peroxidase-conjugated streptavidin (red). (B) The specimens were stained as in (A) except that the antibody was replaced with anti-SSLP-1 antiserum. The slices from castrated mice treated with corn oil (C) or testosterone (D) were also stained as in (B). For contrast, the specimens were further stained with hematoxylin (blue). Photographs were taken with bright-field illumination: MF, mucosal fold; SM, smooth muscle; and LF, luminal fluid. Bar $=50 \mu \mathrm{m}$. smooth muscle layer contained almost none. The strong immunohistochemical staining in the lumen supports the view that SSLP-1 is secreted from the luminal epithelium.

\section{Developmental profiles of Sslp-1 mRNA and protein in seminal vesicles}

The amounts of $S s / p-1$ mRNA in the seminal vesicles of mice at different ages were compared. The RNA message first appeared at a relatively low level in 3-week-old mice. Thereafter, the amount of transcript began increasing rapidly at 4 weeks and reached a maximum in 8-week-old mice (Fig. 7). Similar to the profile of Ss/p1 mRNA, SSLP-1 protein first appeared at a low level in 3 -week-old mice, increased rapidly from 4 weeks, and reached its highest level in 8-week-old mice (not shown).

\section{Effect of testosterone on SsIp-1 gene expression}

The lower levels of SSLP-1 protein in seminal vesicles of pre-puberal animals indicated that $S_{s} / p-1$ gene expression might be under androgen control. To evaluate the effect of testosterone on the $S$ s $/ p$-1 gene expression in seminal vesicle, we compared the findings in castrated and uncastrated mice. The relative levels of $S s / p-1$ mRNA in the seminal vesicles were significantly lower in castrates treated with vehicle only, compared with castrates treated with testosterone (Fig. 8A). Likewise, even with more protein loading in castrates treated with vehicle only, the amount remained lower than in normal adults or castrates treated with testosterone (Fig. 8B). On immunohistochemistry, SSLP-1 protein intensity in the mucosal epithelium of castrates treated with corn oil only (Fig. 6C) was obviously lower than that in normal adults or castrates treated with testosterone (Fig. 6B and D). Taken together, these results suggest that $S$ s $/ p-1$ gene expression in the seminal vesicle is modulated by androgen.

\section{Discussion}

In this study, we have demonstrated that Gm191 gene encoded polypeptide SSLP-1, indeed, is a novel secreted Ly- 6 protein expressed predominantly in the mouse

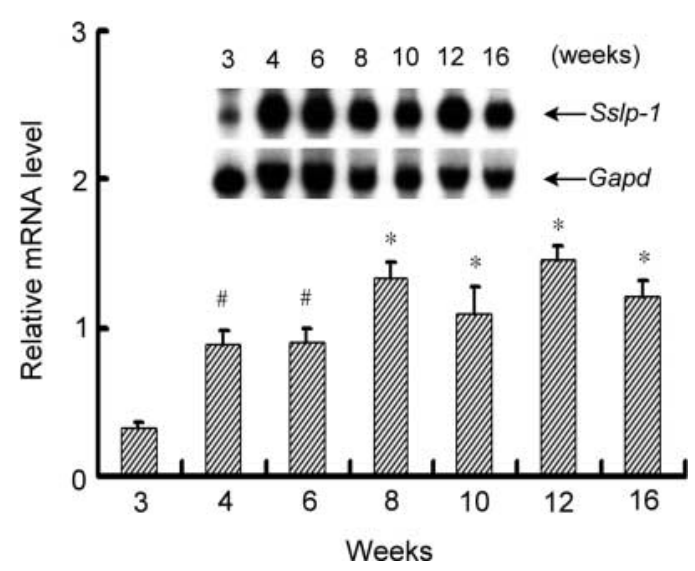

Figure 7 Developmental profile of $S s / p-1$ mRNA in the seminal vesicle. Sslp-1 mRNA and Gapd mRNA in total RNA (20 $\mu$ g) prepared from mouse seminal vesicles at different ages were analyzed by Northern blotting. The relative amounts of $S s / p-1$ mRNA were normalized to the level of the Gapd mRNA on the same blot. Data represent the mean of three repeated experiments and error bars represent the s.D. ${ }^{\#} P<0.01$, ${ }^{*} P<0.001$ in pairwise comparison relative to the mRNA level from the 3 -week-old mice. 


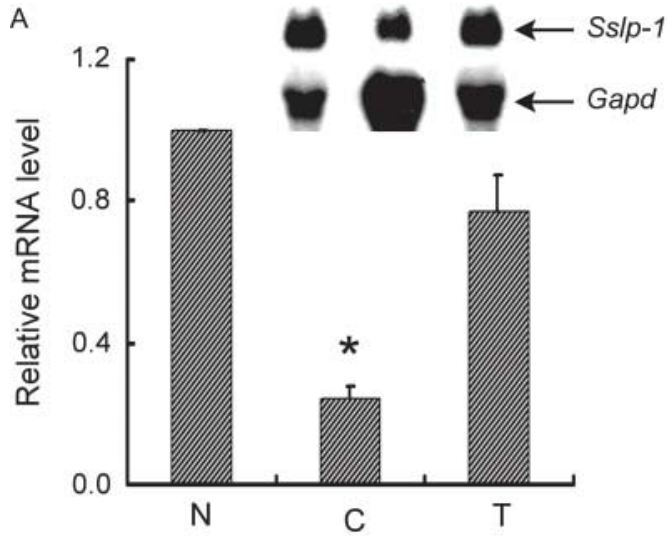

B

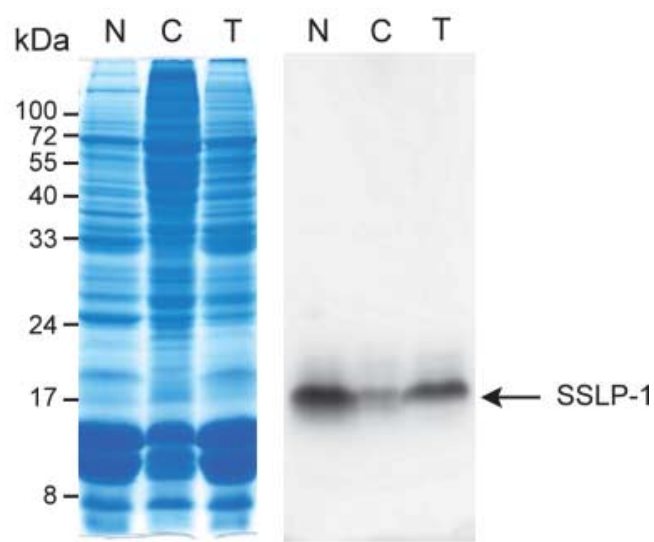

Figure 8 Effect of androgen on Ss/p-1 mRNA and protein expression in the seminal vesicle of adult mice. (A) Northern blotting was conducted to analyze the $S s / p-1$ mRNA expression in total homogenates $(20 \mu \mathrm{g})$ from seminal vesicles of normal adult mice $(\mathrm{N})$, adults castrated 3 weeks previously and treated only with corn oil (C), and adults castrated 3 weeks previously and treated with testosterone propionate in corn oil for 8 consecutive days (T). The relative amounts of $S s / p-1$ mRNA were determined as described in Fig. 7. Data represent the mean of three repeated experiments and error bars represent the S.D. ${ }^{*} P<0.01$ in pairwise comparison relative to the mRNA level from castrates treated with testosterone. (B) Western blot analysis was performed for SSLP-1 protein in tissue homogenates from seminal vesicle samples as in (A). The applied protein amounts were $80 \mu \mathrm{g}$ for $\mathrm{N}$ and $\mathrm{T}$ and $100 \mu \mathrm{g}$ for $\mathrm{C}$.

seminal vesicle. Unlike the GPI-anchored members of the Ly-6/uPAR protein superfamily, the secreted Ly-6 proteins are secreted as indicated by their intraluminal location and the presence of a signal peptide in the sequence.

To recapitulate, the evidence that SSLP-1 is a secreted member of the Ly- 6 protein family includes its purification from SVS and its expression in the lumen and apical region of the mucosal epithelium (Fig. 6). Edman sequencing indicated that SSLP-1 has a 21 amino acid signal peptide (Fig. 3). Removal of the hydrophobic leader sequence gives a protein core consisting of 78 amino acid residues with a molecular mass of $8720 \mathrm{Da}$, which is close to the molecular size of the deglycosylated protein as determined by SDS-PAGE (Fig. 2B).
The results of PAS staining and $\mathrm{N}$-glycosidase $\mathrm{F}$ treatment demonstrate that SSLP-1 is a glycoprotein. The protein contains two potential $\mathrm{N}$-glycosylation sites (Fig. 3), Asn ${ }^{10}$ and $\mathrm{Asn}^{54}$, each being part of consensus Asn-Xaa-(Ser/Thr) (Marshall 1972, Gavel \& von Heijne 1990) in the protein molecule. The results of Edman sequencing suggest that $\mathrm{Asn}^{10}$ is one $\mathrm{N}$-glycosylated site. In contrast with these findings for SSLP-1, SVS7 (Luo et al. 2001), and SLURP-1 (Chimienti et al. 2003) are not glycoproteins, while RUP-1 and RUP-2 have only one predicted $\mathrm{N}$-glycosylation site, and the evidence suggesting that they are glycosylated is indirect (Southan et al. 2002). The function of glycosylation in these secreted proteins remains to be determined.

The Gm191 gene encoding SSLP-1 is the fourth highly expressed gene in the mouse seminal vesicle expressed sequence tag (EST) database (dbEST Library ID.9952). UniGene's EST profileviewer also indicates that it is expressed in male genital tissues and the bladder. However, the BLASTN search of the EST database found its expression in the seminal vesicle, prostate, and bladder. On the other hand, our Northern blotting detected Sslp-1 mRNA only in the seminal vesicle. There was essentially none in the prostate (Fig. 5) and bladder (data not shown). In contrast to our findings for Sslp-1, another Ly- 6 gene Svs7 encoding for a secreted protein had far lower expression levels in the mouse seminal vesicle when blasting the EST database using the Svs7 CDNA sequence as the query.

There are several similarities between SSLP-1 and SVS7, including the same gene locus in chromosome 9, tissue-specific expression and localization in the mouse seminal vesicle, and conserved cysteine positions that are a feature of the secreted Ly-6 protein subfamily. However, they differ in terms of glycosylation and have low sequence identities. These differences suggest that they may have different functions, although this remains to be determined.

The growth and differentiation of the seminal vesicle are closely associated with androgens (Chai 1956, Morley \& Wright 1972). Castration caused atrophy of adult seminal vesicles and, in this study, an apparent decrease in seminal vesicle $S s / p-1$ mRNA and protein levels. Testosterone administration for castrated animals largely restored the seminal vesicles to a hypertrophied state with a considerable amount of $S s / p-1$ mRNA and protein, comparable to that of non-castrated animals (Figs 6 and 8). Similar results have also been demonstrated for other androgen-dependent genes in the seminal vesicles (Higgins et al. 1976, Chen et al. 1987, 1998, Huang et al. 1999, Li et al. 2005). With the limited promoter sequence of the $S s / p-1$ gene, we could not find an androgen-response element that would allow direct regulation of transcription. This needs to be investigated further to determine whether the $S$ s $I p-1$ gene promoter contains androgen-response elements. Alternatively, rather than being under direct androgen control, Sslp-1 
transcription could be regulated by other transcription factors that are themselves under androgen control.

In conclusion, we have identified a novel secreted Ly-6 protein and demonstrated its tissue-specific expression in the mouse seminal vesicle. The amount of Sslp-1 mRNA and protein in the seminal vesicle is modulated by androgen and correlates with the stage of animal maturation, suggesting that SSLP-1 may play a role in male reproduction. Its exact function and role in male reproduction remain to be determined.

\section{Acknowledgements}

This work is supported by grants of Mackay Memorial Hospital, MMH 9546 to $\mathrm{M}-\mathrm{H}$ Lin and MMH 9556 to S-H $\mathrm{Li}$, respectively. The authors declare that there is no conflict of interest that would prejudice the impartiality of this scientific work.

\section{References}

Adermann K, Wattler F, Wattler S, Heine G, Meyer M, Forssmann WG \& Nehls M 1999 Structural and phylogenetic characterization of human SLURP-1, the first secreted mammalian member of the Ly6/uPAR protein superfamily. Protein Science 8 810-819.

Bamezai A 2004 Mouse Ly-6 proteins and their extended family: markers of cell differentiation and regulators of cell signaling. Archivum Immunologiae et Therapiae Experimentalis 52 255-266.

Chai CK 1956 Seminal vesicle growth as a function of androgen stimulation in mice. American Journal of Physiology 186 463-467.

Chen YH, Pentecost BT, McLachlan JA \& Teng CT 1987 The androgendependent mouse seminal vesicle secretory protein IV: characterization and complementary deoxyribonucleic acid cloning. Molecular Endocrinology 1 707-716.

Chen LY, Lin YH, Lai ML \& Chen YH 1998 Developmental profile of a caltrin-like protease inhibitor, P12, in mouse seminal vesicle and characterization of its binding sites on sperm surface. Biology of Reproduction 59 1498-1505.

Chimienti F, Hogg RC, Plantard L, Lehmann C, Brakch N, Fischer J, Huber M, Bertrand D \& Hohl D 2003 Identification of SLURP-1 as an epidermal neuromodulator explains the clinical phenotype of Mal de Meleda. Human Molecular Genetics 12 3017-3024.

Coronel CE, Winnica DE, Novella ML \& Lardy HA 1992 Purification, structure, and characterization of caltrin proteins from seminal vesicle of the rat and mouse. Journal of Biological Chemistry $\mathbf{2 6 7}$ 20909-20915.

Eckl KM, Stevens HP, Lestringant GG, Westenberger-Treumann $M$, Traupe H, Hinz B, Frossard PM, Stadler R, Leigh IM, Nurnberg P, et al. 2003 Mal de Meleda (MDM) caused by mutations in the gene for SLURP-1 in patients from Germany, Turkey, Palestine, and the United Arab Emirates. Human Genetics 112 50-56.

Fischer J, Bouadjar B, Heilig R, Huber M, Lefevre C, Jobard F, Macari F, Bakija-Konsuo A, Ait-Belkacem F, Weissenbach J, et al. 2001 Mutations in the gene encoding SLURP-1 in Mal de Meleda. Human Molecular Genetics 10 875-880.

Gavel Y \& von Heijne G 1990 Sequence differences between glycosylated and non-glycosylated Asn-X-Thr/Ser acceptor sites: implications for protein engineering. Protein Engineering 3 433-442.
Gumley TP, McKenzie IF \& Sandrin MS 1995 Tissue expression, structure and function of the murine Ly- 6 family of molecules. Immunology and Cell Biology 73 277-296.

Higgins SJ, Burchell JM \& Mainwaring WI 1976 Androgen-dependent synthesis of basic secretory proteins by the rat seminal vesicle. Biochemical Journal 158 271-282.

Huang YH, Chu ST \& Chen YH 1999 Seminal vesicle autoantigen, a novel phospholipid-binding protein secreted from luminal epithelium of mouse seminal vesicle, exhibits the ability to suppress mouse sperm motility. Biochemical Journal 343 241-248.

Laemmli UK 1970 Cleavage of structural proteins during the assembly of the head of bacteriophage T4. Nature 227 680-685.

LeClair KP, Palfree RG, Flood PM, Hammerling U \& Bothwell A 1986 Isolation of a murine Ly- 6 cDNA reveals a new multigene family. EMBO Journal 5 3227-3234.

Li SH, Lee RK, Hsiao YL \& Chen YH 2005 Demonstration of a glycoprotein derived from the Ceacam10 gene in mouse seminal vesicle secretions. Biology of Reproduction 73 546-553.

Luo CW, Lin HJ \& Chen YH 2001 A novel heat-labile phospholipidbinding protein, SVS VII, in mouse seminal vesicle as a sperm motility enhancer. Journal of Biological Chemistry 276 6913-6921.

Maniatis T, Fritsch EF \& Sambrook J 1989 Molecular Cloning, New York: Cold Spring Harbor Laboratory, Cold Spring Harbor, pp 7.46.

Marshall RD 1972 Glycoproteins. Annual Review of Biochemistry 41 673-702.

Morley AR \& Wright NA 1972 Androgen-induced cell proliferation and differentiation in the seminal vesicle and coagulating gland of the castrated mouse. Journal of Endocrinology 54 465-471.

Mastrangeli R, Donini S, Kelton CA, He C, Bressan A, Milazzo F, Ciolli V, Borrelli F, Martelli F, Biffoni M, et al. 2003 ARS component $\mathrm{B}$ : structural characterization, tissue expression and regulation of the gene and protein (SLURP-1) associated with Mal de Meleda. European Journal of Dermatology 13 560-570.

Smith PK, Krohn RI, Hermanson GT, Mallia AK, Gartner FH, Provenzano MD, Fujimoto EK, Goeke NM, Olson BJ \& Klenk DC 1985 Measurement of protein using bicinchoninic acid. Analytical Biochemistry $15076-85$.

Southan C, Cutler P, Birrell H, Connell J, Fantom KG, Sims M, Shaikh N \& Schneider K 2002 The characterisation of novel secreted Ly-6 proteins from rat urine by the combined use of two-dimensional gel electrophoresis, microbore high performance liquid chromatography and expressed sequence tag data. Proteomics 2 187-196.

Tarentino AL \& Plummer TH Jr 1994 Enzymatic deglycosylation of asparagine-linked glycans: purification, properties, and specificity of oligosaccharide-cleaving enzymes from Flavobacterium meningosepticum. Methods in Enzymology 230 44-57.

Tsuji H, Okamoto K, Matsuzaka Y, lizuka H, Tamiya G \& Inoko H 2003 SLURP-2, a novel member of the human Ly- 6 superfamily that is up-regulated in psoriasis vulgaris. Genomics 81 26-33.

Ward KM, Yerebakan O, Yilmaz E \& Celebi JT 2003 Identification of recurrent mutations in the ARS (component B) gene encoding SLURP-1 in two families with mal de Meleda. Journal of Investigative Dermatology 120 96-98.

Received 14 March 2006

First decision 27 April 2006

Revised manuscript received 1 June 2006

Accepted 13 June 2006 